\title{
ENHANCED CONTROL EFFECTOR DESIGNS FOR AIRBREATHING TRANSATMOSPHERIC VEHICLES
}

\author{
Charles E. Cockrell, Jr.* and John D. McMinn ${ }^{\dagger}$ \\ NASA Langley Research Center, Hampton, VA
}

\begin{abstract}
$\underline{\text { Abstract }}$
A study was conducted to evaluate the potential effectiveness of a moveable cowl-trailing-edge design for airbreathing hypersonic single-stage-to-orbit (SSTO) configurations, which can be extended or deflected from the nominal position in order to provide additional pitching moment capability. This additional pitching moment capability may reduce the necessary deflection angle from conventional control surfaces and the associated trim drag penalty. Calculations for a generic SSTO configuration with baseline and modified cowl trailing edge geometries were performed at Mach 6 and 10 initially with an engineering analysis code in order to examine several design parametrics. In order to more accurately model geometries and flow physics, 2-D viscous computational fluid dynamics (CFD) predictions were obtained. FInally, a limited set of 3D CFD predictions were obtained at Mach 6 in order to show the effects of modeling $3 \mathrm{D}$ flow fields as well as the full 3D vehicle geometry. Comparisons of aftbody surface pressures and force and moment predictions show differences between initial predictions and 2-D CFD solutions due to geometry modeling and calculation method differences. The 3-D CFD predictions confirm the trends observed in the 2-D solutions and provide additional information on 3D effects. These analyses shows that cowltrailing-edge extensions were effective in providing additional (nose-down) pitching moment increments as well as increased thrust compared to the baseline geometry. These effects reduce the control surface deflection angle required to trim the vehicle and the associated trim drag. Cowl-trailingedge deflections were not as effective, generating more noseup pitching moment and decreased thrust compared to nondeflected cases.
\end{abstract}

\section{$\underline{\text { Nomenclature }}$}

$\begin{array}{ll}\text { A } & \text { Projected area, } \mathrm{m}^{2} \\ \bar{c} & \text { Reference length, } \mathrm{m} \\ \mathrm{C}_{\mathrm{p}} & \text { Pressure coefficient } \\ \mathrm{C}_{\mathrm{L}} & \text { Lift coefficient } \\ \mathrm{C}_{\mathrm{M}} & \text { Pitching moment coefficient (nose-up positive) } \\ \mathrm{C}_{\mathrm{T}} & \text { Thrust coefficient } \\ \mathrm{L} & \text { Moment arm length } \\ \mathrm{P} & \text { Static pressure, N/m } \\ \mathrm{q} & \text { Dynamic pressure, } \mathrm{N} / \mathrm{m}^{2} \\ \mathrm{~S}_{\text {ref }} & \text { Reference planform area, } \mathrm{m}^{2}\end{array}$

\footnotetext{
* Aerospace Engineer, Hypersonic Airbreathing Propulsion Branch, Aero and Gas Dynamics Division, Member AIAA. †Aerospace Engineer, Dynamics and Control Branch, Flight Dynamics and Control Division, Member AIAA.
}

\begin{tabular}{|c|c|}
\hline $\mathrm{x}, \mathrm{y}, \mathrm{z}$ & Cartesian coordinates \\
\hline $\mathrm{y}^{+}$ & Grid spacing parameter \\
\hline$\delta$ & $\begin{array}{l}\text { Cowl trailing edge deflection angle, deg } \\
\text { (trailing-edge down positive) }\end{array}$ \\
\hline$\xi, \eta, \zeta$ & Computational coordinates \\
\hline \multicolumn{2}{|c|}{ Subscripts } \\
\hline o & Moment reference center coordinate \\
\hline xy & Projected quantity in the $x-y$ plane \\
\hline yz & Projected quantity in the $y-z$ plane \\
\hline $\mathrm{x}$ & Quantity in the $\mathrm{x}$-direction \\
\hline $\mathrm{z}$ & Quantity in the z-direction \\
\hline$\infty$ & Freestream quantity \\
\hline
\end{tabular}

\section{Introduction}

Hypersonic airbreathing transatmospheric vehicles (ATVs) are candidates for providing low cost, efficient access to space. Horizontal takeoff (SSTO) configurations utilizing airframe-integrated scramjet propulsion systems have been the subject of numerous studies. One characteristic of ATV configurations is that the propulsion system must be highly integrated with the airframe of the vehicle. This high degree of propulsion/airframe integration along with the challenges of hypersonic flight lead to unique stability and control problems. One such problem is that, at higher Mach numbers, aerodynamic control effectiveness is greatly reduced. The general trend for this class of vehicle is that as the aircraft accelerates to orbital velocity, the aerodynamic center moves forward of the center of gravity, producing a nose-up pitching moment for the full vehicle. ${ }^{1,2}$ This nose-up pitching may exist despite the high surface pressures produced by the impact of scramjet exhaust flows on the vehicle aftbody, when used as an external nozzle surface. The conventional means of providing a balancing trim moment is through deflections of aerodynamic control surfaces. However, at hypersonic speeds, even moderate deflections produce a significant trim drag. ${ }^{1,2}$ Therefore, it is desirable to develop alternative methods for providing additional pitching moment capability and decreasing the necessary control surface deflection angle required.

One possible control effector design that may enhance vehicle stability and control is a moveable cowl trailing edge surface that can be extended or deflected from the nominal position to provide an additional pitch trim capability. An extension of the cowl trailing edge is expected to increase the surface pressures on the aftbody/external nozzle surface and provide an additional nose-down pitching moment capability as well as increases in lift and thrust. Deflections of the cowl trailing edge into the freestream may also provide additional pitching moment capability. The effects of these modifica- 
tions on a generic SSTO configuration were examined in this study. The objective was to determine if cowl trailing edge extensions and deflections were effective at providing favorable force and moment increments. Engineering analysis code predictions, using the NASA-Langley- developed code SRGULL, were obtained as well as 2-D and 3-D viscous CFD predictions in order to show the effects of moving the cowl trailing edge on flow field characteristics, surface pressures and forces and moments.

A secondary objective of this study is to provide comparisons of the various analysis methods. The 2D SRGULL predictions provide reasonable approximations for a large number of design parametrics based on simplified assumptions without a great expense of computer resources. The 2D CFD solutions more accurately model the geometry as well as the flow physics of the problem. The 3D predictions account for 3D flow field effects and model the full vehicle geometry, including wing surfaces.

This paper includes a description of the configuration geometry and the modeling of engine cowl-trailing-edge extensions and deflections. The methodologies of the engineering code and CFD analyses are presented with a description of flow conditions assumed. The results are presented by showing CFD flow-field solutions, increments in forces and moments due to cowl extensions and deflections from the baseline geometry and comparisons of aftbody (external nozzle) surface pressures from both sets of predictions.

\section{Configuration Geometry}

The configuration chosen for this study is known as the test technique demonstrator (TTD). The TTD is a generic SSTO configuration which has been the subject of numerous experimental and computational studies involving simulation of powered scramjet exhaust flow fields. ${ }^{2-12}$ Sketches of the TTD geometry are shown in figure 1 . The full-scale TTD configuration is 42.672 meters (1680 inches) in length with a wing span of 10.16 meters (400 inches). A detailed description of the TTD geometry is included in reference 13 .

Two different representations of the TTD engine inlet are shown in figure 1. The first is a flow-through inlet and the second is a faired-over inlet designed to divert the forebody flow field around the engine cowl. The flow-through inlet representation was used in obtaining the initial engineering analysis code predictions. This analysis modeled the inlet flow field as well as the combustor. The faired-over inlet was used to obtain the CFD predictions. This representation is similar to the experimental technique used to simulate powered scramjet exhaust flow fields in ground test facilities, so CFD results may be compared to experimental data. The experimental technique is to route a simulant gas on board the test model to simulate the exhaust flow by expelling the test gas through the internal nozzle. ${ }^{2}$ Therefore, the forebody flow cannot be ingested into the inlet and the fairing must be in place to divert the forebody flow around the external cowl.

The exhaust flow field in the CFD solutions was modeled by specifying initial conditions at the combustor exit plane. Previous computational studies have indicated that the inlet rep-
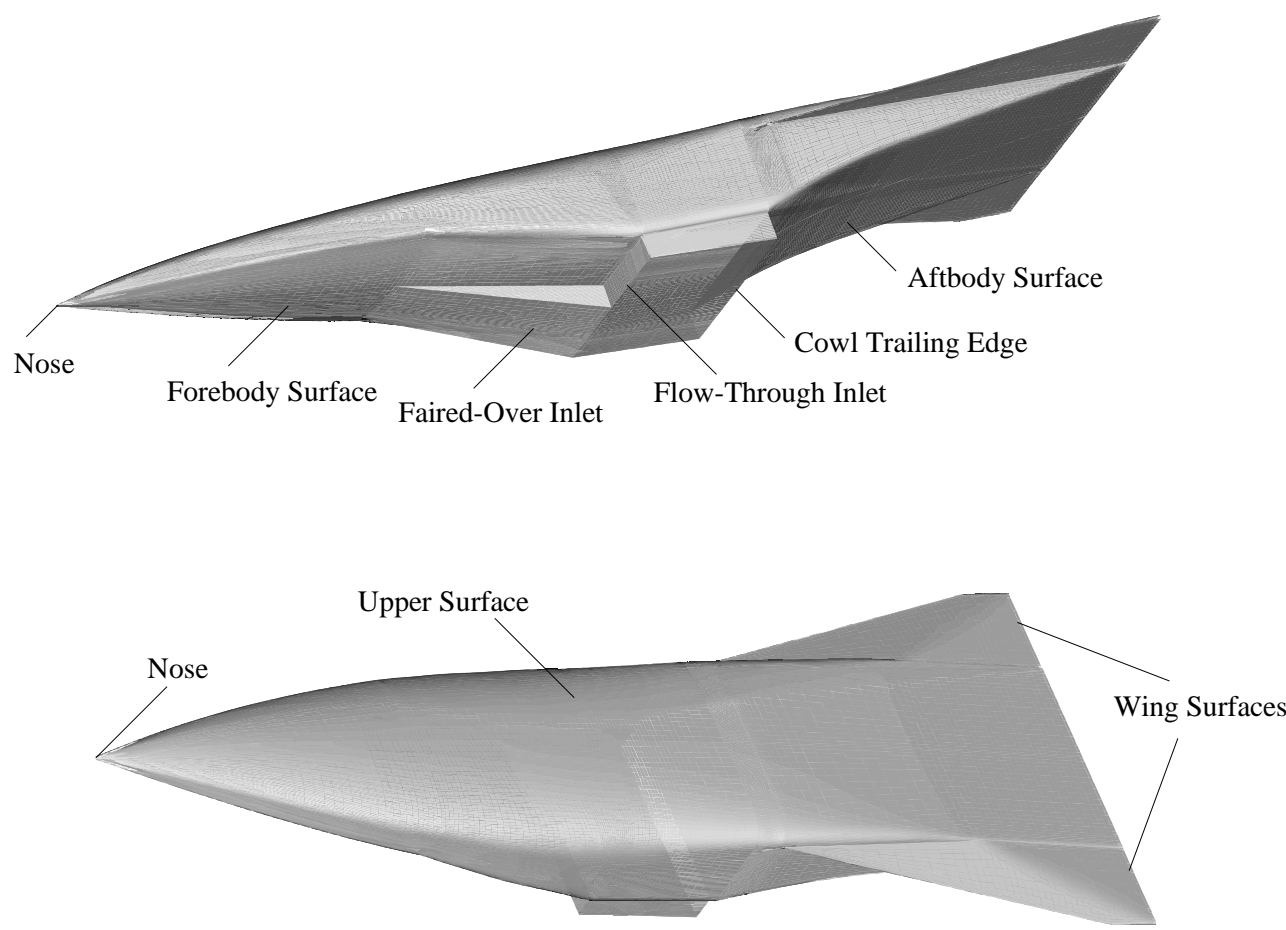

Figure 1. Sketch of TTD configuration geometry. 


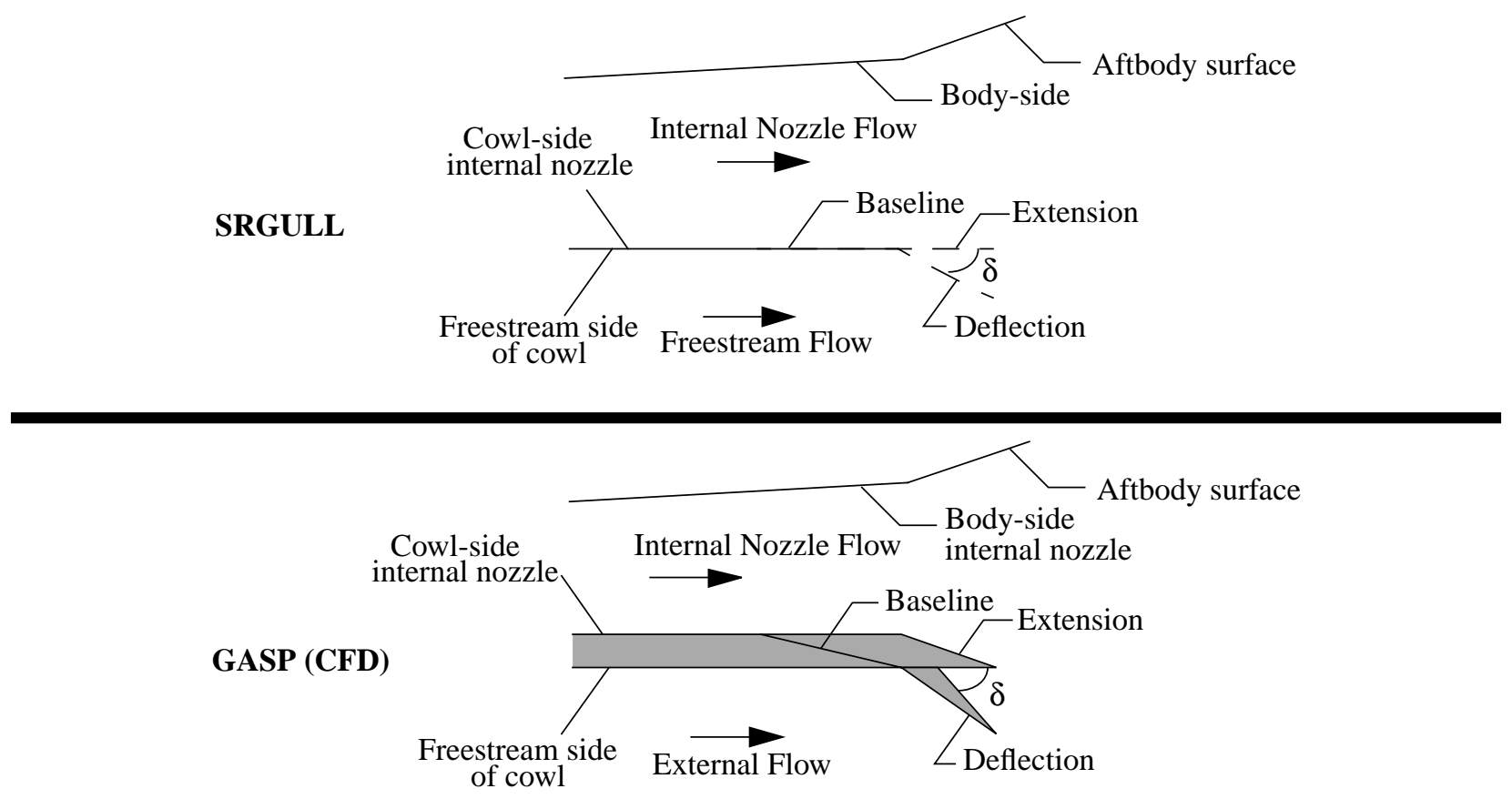

Figure 2. Modeling of cowl-trailing-edge geometry.

resentation has little significant effect on the aftbody surface pressures or on the aftbody forces and moments of the configuration because the expanding exhaust plume isolates the aftbody flow field from the forebody/inlet flow. ${ }^{3}$

In order to investigate the effects of a moveable cowl trailing edge, various combinations of trailing-edge extensions and deflections from the baseline geometry were studied. A 0.508-meter (20-inch) cowl-trailing-edge extension with $0^{\circ}, 5^{\circ}$ and $10^{\circ}$ deflections (trailing edge down) and a 1.016-meter (40-inch) extension with $0^{\circ}$ and $5^{\circ}$ deflections were examined. A schematic of the 2-D cowl-trailing-edge geometry for each analysis is shown in figure 2. For deflections of the cowl trailing edge, the streamwise location of the trailing edge point remained the same as for the $0^{\circ}$ deflection ( $x=26.774$ meters, referenced from the nose of the vehicle). The engine cowl was modeled with a finite thickness which tapers to a sharp point in the CFD analysis. In contrast, the engineering code predictions consisted of a quasi 1-D analysis which modeled only the streamwise locations of the cowl stations. Note that the geometry in figure 2 is not drawn to scale and is only intended to show the conceptual modeling of each geometry modification. For the 3-D CFD analysis, the engine sidewalls were also extended to match the $\mathrm{x}$-station of the trailing-edge point.

\section{Method}

The initial engineering analysis was conducted using the SRGULL code, which is actually a combination of two $\operatorname{codes}^{14}$. The first utilizes a 2D inviscid method to calculate the external forebody, internal inlet, internal nozzle and aftbody flowfields. The second utilizes a quasi-1D analysis of the internal combustion process with scheduled mixing and

\begin{tabular}{|l|l|l|}
\hline & Mach 6 & Mach 10 \\
\hline \hline Density $\left(\mathrm{kg} / \mathrm{m}^{3}\right)$ & 0.06026 & 0.02105 \\
\hline Temperature $(\mathrm{K})$ & 219.3 & 225.7 \\
\hline Static pressure $\left(\mathrm{N} / \mathrm{m}^{2}\right)$ & 3793 & 1363 \\
\hline Dynamic pressure $\left(\mathrm{N} / \mathrm{m}^{2}\right)$ & 95587 & 95435 \\
\hline Altitude $(\mathrm{m})$ & 22350 & 29000 \\
\hline Reynolds No. $\left(\mathrm{x} 10^{6} / \mathrm{m}\right)$ & 7.47 & 4.31 \\
\hline
\end{tabular}

Table 1. Freestream conditions specified for analysis.

reaction. The flow fields along the vehicle upper surface and below the external cowl are not computed. Freestream conditions are assumed at the cowl trailing edge location below the external cowl. A schematic of the 2-D geometry with each component labeled is shown in figure 3 . This drawing shows both the flow-through inlet representation used in the SRGULL analysis and the faired-over inlet used in the CFD analysis. Approximations for skin friction, using an integral boundary layer method, and heat losses for the forebody, inlet, combustor, internal nozzle and aftbody surfaces are included in the force and moment predictions generated by SRGULL. Predictions were obtained for representative flight conditions at freestream Mach numbers of 6 and 10. A summary of freestream conditions specified is shown in table 1 . The combustion cycle analysis in SRGULL models angular injection of hydrogen fuel into the combustion chamber with an appropriate mixing and reaction schedule. SRGULL computes the gas composition and other flow-field properties at 


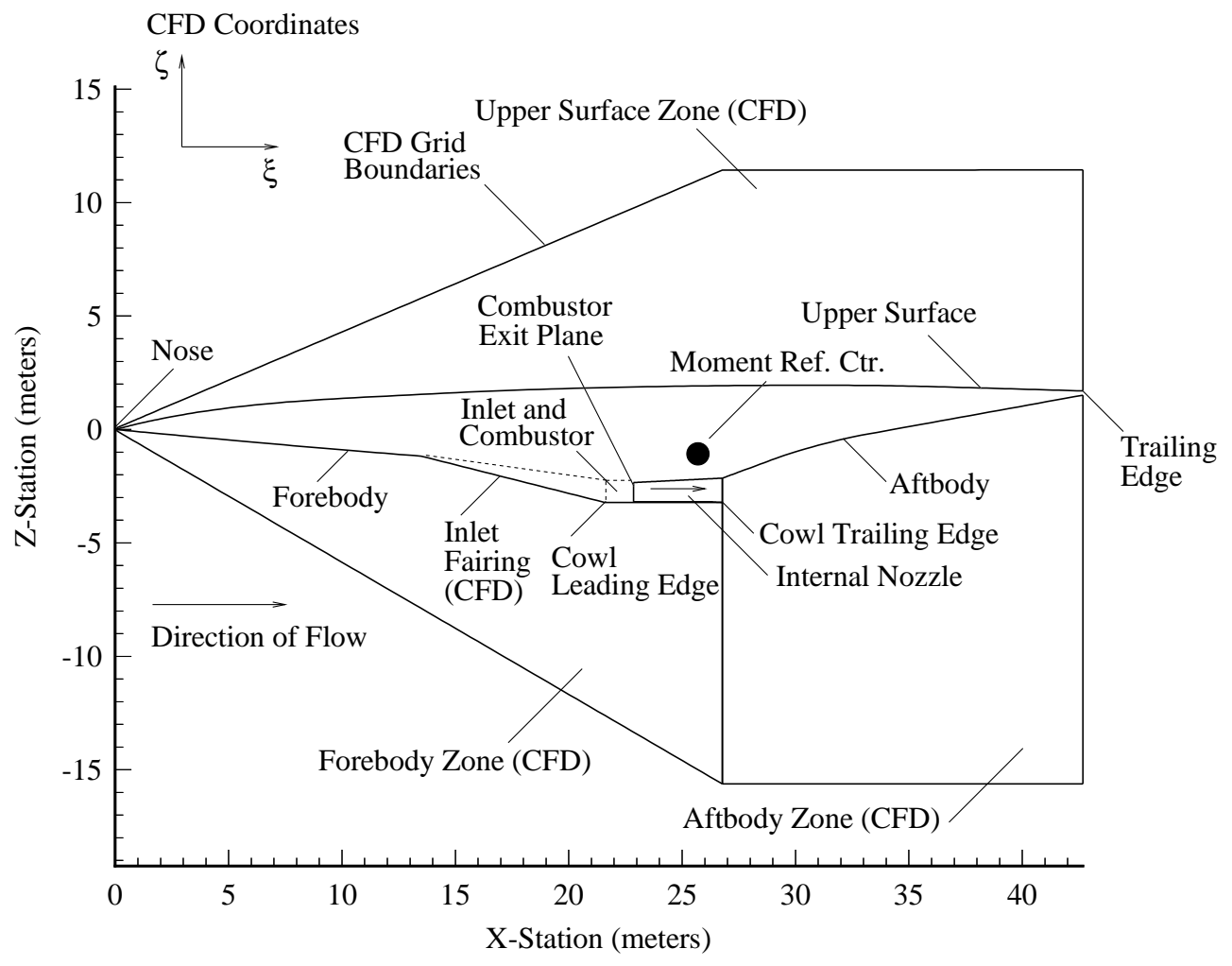

Figure 3. 2-D geometry with components and CFD grid topology.

the combustor exit plane location. Frozen flow is then assumed downstream of this location. Based on values used in previous studies of similar configurations at representative flight conditions, a hydrogen fuel flow rate of $20 \mathrm{~kg} / \mathrm{sec}$ was specified for all cases. This corresponds to fuel equivalence ratios of 0.45 and 0.51 for the Mach 6 and Mach 10 cases, respectively.

The CFD predictions were obtained using the General Aerodynamic Simulation Program (GASP), version 2.2, developed by Aerosoft, Inc. ${ }^{5}$ Two-dimensional solutions of the parabolized Navier-Stokes (PNS) equations were obtained using the same freestream conditions listed in table 1. As indicated previously, the procedure used was to model the exhaust flow field by specifying initial conditions at the combustor exit plane. These conditions were taken from the SRGULL calculations and are shown in table 2 . This table lists the mass fractions of the constituents modeled as well as Mach number, temperature and mixture density of the exhaust gas. No further combustion (i.e., frozen flow) was modeled downstream of the combustor exit plane location. The aftbody flow field was calculated by allowing the internal nozzle and external forebody flow fields to mix diffusively beginning at the cowl trailing edge location. This procedure has been used in previous studies involving scramjet exhaust flow simulation and is described in detail in reference 5 . The forebody and aftbody zones modeled air as a thermally-per-

\begin{tabular}{|l|l|l|}
\hline & Mach 6 & Mach 10 \\
\hline \hline Mach Number & 1.502 & 2.974 \\
\hline Temperature $(\mathrm{K})$ & 1871 & 2057 \\
\hline Mixture Density $\left(\mathrm{kg} / \mathrm{m}^{3}\right)$ & 0.1788 & 0.0766 \\
\hline Mass Fraction of $\mathrm{H}_{2} \mathrm{O}$ & 0.1047 & 0.1164 \\
\hline Mass Fraction of $\mathrm{O}_{2}$ & 0.1347 & 0.1222 \\
\hline Mass Fraction of $\mathrm{H}_{2}$ & 0.001311 & 0.001492 \\
\hline Mass Fraction of $\mathrm{N}_{2}$ & 0.7454 & 0.7442 \\
\hline Mass Friction of $\mathrm{Ar}$ & 0.01310 & 0.01308 \\
\hline Mass Fraction of $\mathrm{OH}$ & 0.0007062 & 0.002270 \\
\hline
\end{tabular}

Table 2. Species concentrations and flow-field conditions at combustor exit plane.

fect gas with specific heat ratios varying as a function of temperature. Table 3 shows the number of mesh points used in each of the zones indicated in figure 3 for the 2-D computational grid. Solution convergence was obtained by reducing the L2-norm of the residual vector by 4 to 5 orders of magni- 


\begin{tabular}{|l|l|l|}
\hline \multicolumn{1}{|c|}{ Zone } & \multicolumn{1}{c|}{$\xi$-direction } & \multicolumn{1}{c|}{$\zeta$-direction } \\
\hline \hline Upper Surface & 131 & 91 \\
\hline Forebody & 91 & 141 \\
\hline Internal Nozzle & 81 & 111 \\
\hline Aftbody & 61 & 251 \\
\hline
\end{tabular}

Table 3. Number of mesh points used in 2-D CFD grids.

tude. Proper grid spacing to resolve boundary layers was ensured by examining the grid spacing parameter, $\mathrm{y}^{+}$, which has been defined in previous studies. ${ }^{16}$ Typically, $\mathrm{y}^{+}$values on the order of 1 are adequate to ensure proper grid spacing. The Baldwin-Lomax algebraic model was utilized for turbulent boundary layers. A point transition model was used with the transition location predicted by SRGULL. Force and moment predictions for each case were obtained by integrating surface pressure coefficient values. The equations for pressure integration are shown below for clarity.

$$
\begin{aligned}
\mathrm{C}_{\mathrm{L}} & =\frac{\int\left(\mathrm{P}-\mathrm{P}_{\infty}\right)\left(\mathrm{A}_{\mathrm{xy}}\right)}{\mathrm{q}_{\infty} \mathrm{S}_{\mathrm{ref}}}, \\
\mathrm{C}_{\mathrm{T}} & =\frac{\int\left(\mathrm{P}-\mathrm{P}_{\infty}\right)\left(\mathrm{A}_{\mathrm{yz}}\right)}{\mathrm{q}_{\infty} \mathrm{S}_{\mathrm{ref}}}, \text { and } \\
\mathrm{C}_{\mathrm{M}} & =\frac{\int\left(\mathrm{P}-\mathrm{P}_{\infty}\right)\left(\mathrm{A}_{\mathrm{xy}}\right)\left(\mathrm{L}_{\mathrm{x}}\right)}{\mathrm{q}_{\infty} \mathrm{S}_{\mathrm{ref}} \overline{\mathrm{c}}}+\frac{\int\left(\mathrm{P}-\mathrm{P}_{\infty}\right)\left(\mathrm{A}_{\mathrm{yz}}\right)\left(\mathrm{L}_{\mathrm{z}}\right)}{\mathrm{q}_{\infty} \mathrm{S}_{\mathrm{ref}} \overline{\mathrm{c}}}
\end{aligned}
$$

Viscous force components were calculated by integrating skin friction coefficient values. All force and moment coefficients listed included both inviscid and viscous force components. Values for freestream static and dynamic pressure, $\mathrm{p}_{\infty}$ and $\mathrm{q}_{\infty}$, are shown in table 1 . The moment reference center used was at a location equal to approximately 60 percent of the total vehicle length $\left(\mathrm{x}_{\mathrm{o}}=25.63, \mathrm{y}_{\mathrm{o}}=0.0\right.$ and $\mathrm{z}_{\mathrm{o}}=-1.03$ meters), as indicated in figure 3 . The reference planform area used was the full-span planform area $\left(\mathrm{S}_{\mathrm{ref}}=519.482 \mathrm{~m}^{2}\right)$ and the reference length used was the distance from the point where the wing apex is projected to the vehicle center line to the vehicle trailing edge ( $\mathrm{c}=30.42$ meters).

Three-dimensional solutions of this configuration were also obtained for a limited number of cases in order to show the effects of modeling the full 3-D geometry and flow field. These included the baseline geometry at Mach 6 as well as a 0.508 -meter (20-inch) cowl-trailing-edge extension with $0^{\circ}$ and $10^{\circ}$ deflections. This analysis followed the same general computational procedure used for the 2-D solutions and used the same moment reference center and reference quantities. Since this analysis was intended to show general trends

\begin{tabular}{|l|c|c|l|}
\hline \multicolumn{1}{|c|}{ Zone } & $\xi$ & $\eta$ & \multicolumn{1}{c|}{$\zeta$} \\
\hline \hline Forebody & 107 & 157 & 99 \\
\hline Internal Nozzle & 61 & 101 & 101 \\
\hline Aftbody & 73 & 147 & 99 \\
\hline
\end{tabular}

Table 4. Number of mesh points used in 3-D CFD grids.

for the full 3-D geometry and an accurate assessment of the boundary layer would require a large expense in computer resources, the boundary layer was assumed to be fully laminar on all surfaces. The same freestream conditions shown in table 1 were also used for the 3-D solutions. The grid topology is also identical with the exception that the upper surface is no longer a separate zone. The forebody zone for the 3-D solutions consists of the entire vehicle surface from the nose to the cowl trailing edge. The aftbody zone models the vehicle from the cowl trailing edge downstream. The number of grid points in each computational zone for the 3-D solutions is shown in table 4 . The $\eta$ direction now corresponds to the circumferential direction for the forebody and aftbody zones (starting at the upper symmetry plane and ending at the lower symmetry plane) and to the spanwise direction for the internal nozzle zone.

\section{Results and Discussion}

A 2-D CFD flow-field solution at Mach 6 freestream conditions for the baseline geometry (no cowl extensions or deflections) is shown in figure 4. This figure shows Mach number contours and qualitatively illustrates the salient flowfield features present. Shocks are produced by the forebody surface and the inlet fairing. A shear layer defines the extent of the exhaust plume, which propagates downstream from the cowl exit plane. Two plume shocks are generated by the presence of the exhaust plume. The internal plume shock is caused by the exhaust jet turning back into alignment with the freestream after the initial expansion as it exits the internal nozzle. The external plume shock is caused by the turning of the freestream flow as it impacts the shear layer downstream of the cowl trailing edge. CFD flow-field predictions indicate that these flow-field features are not significantly altered by the cowl trailing edge extensions or deflections examined. For comparative purposes, a 2-D flow-field solution of the baseline configuration at Mach 10 freestream conditions is shown in figure 5 .

Predictions for aftbody surface pressures, from the cowl exit plane location to the vehicle trailing edge, are shown in figures 6 through 9 for both SRGULL and 2-D GASP solutions. Pressure coefficient values are shown as a function of the streamwise distance from the nose of the configuration. Figure 6 shows the effect of cowl-trailing-edge 


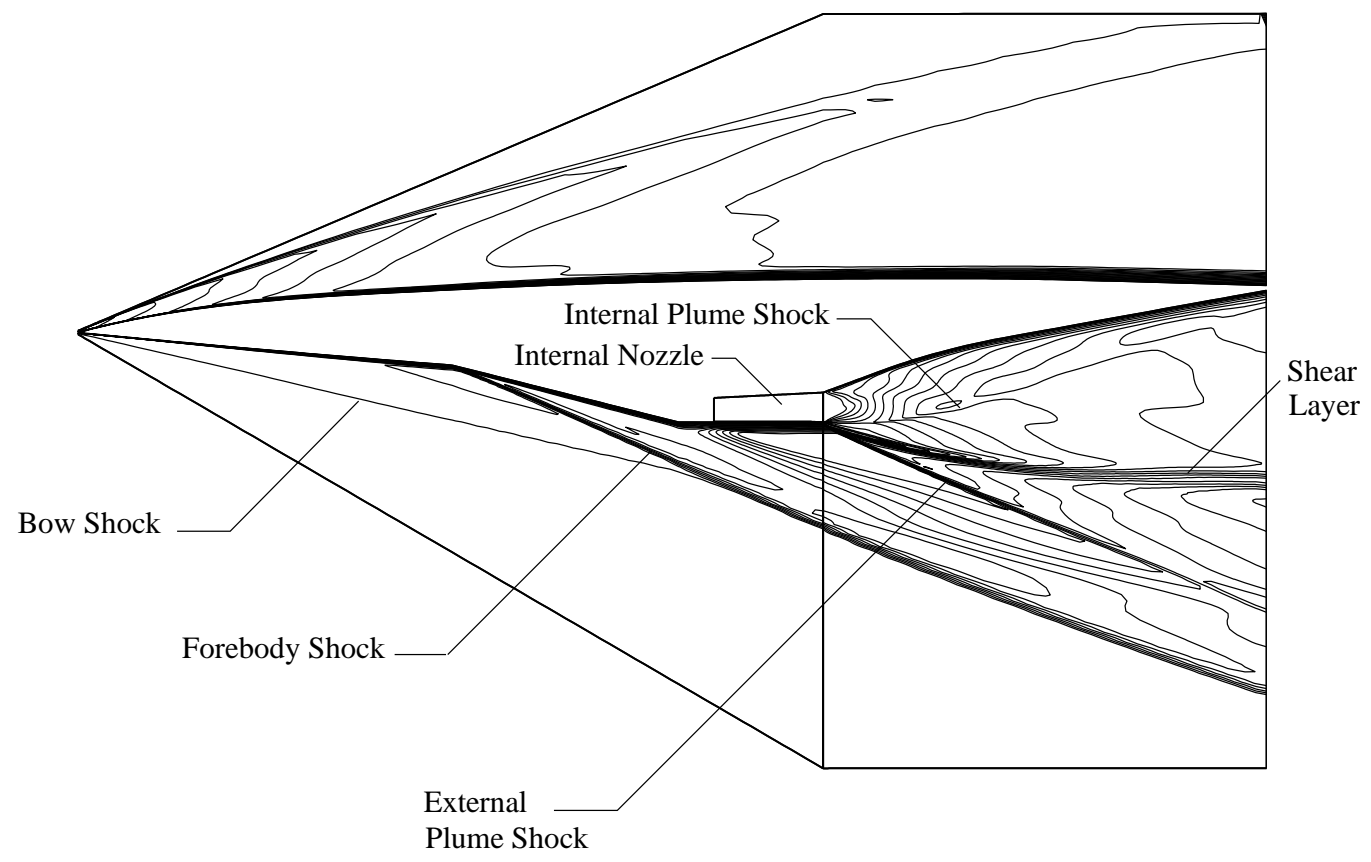

Figure 4. Mach number contours from 2-D CFD solution of baseline geometry at Mach 6 freestream conditions.

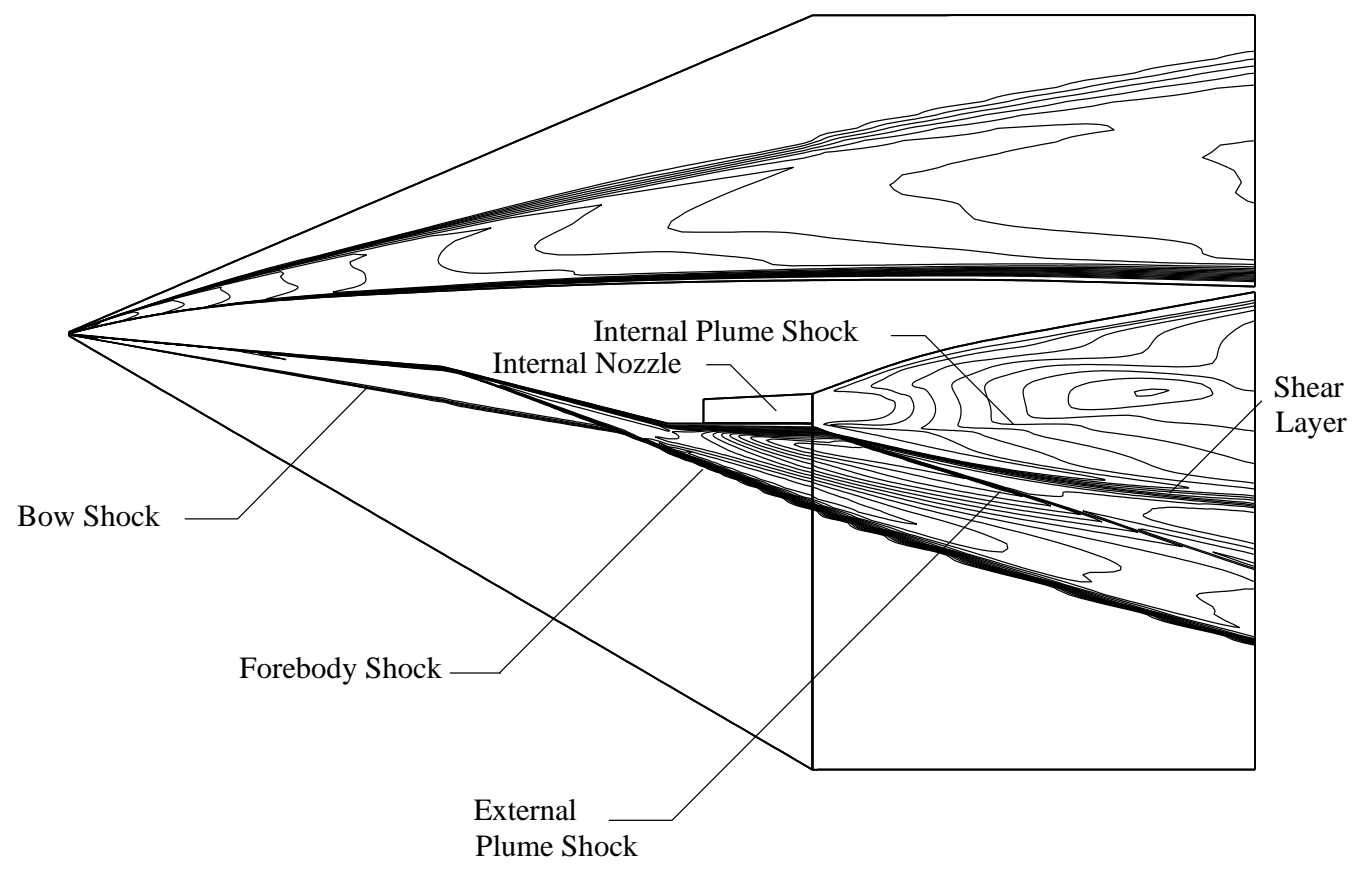

Figure 5. Mach number contours from 2-D CFD solution of baseline geometry at Mach 10 freestream conditions. 


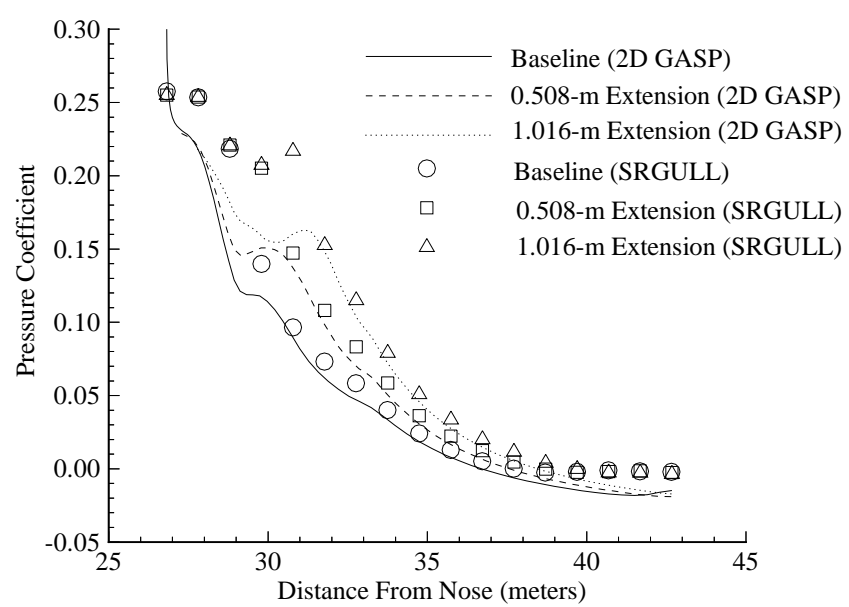

Figure 6. Effect of cowl-trailing-edge extensions on aftbody surface pressures at Mach 6.

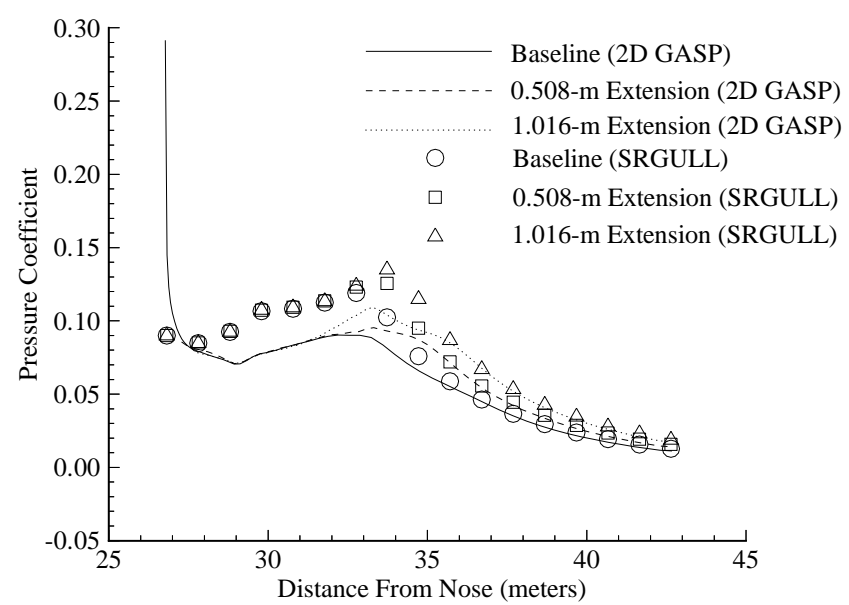

Figure 8. Effect of cowl-trailing-edge extensions on aftbody surface pressures at Mach 10.

extensions on aftbody surface pressures at Mach 6 freestream conditions. A comparison between 2-D GASP and SRGULL values shows that SRGULL predicts higher surface pressures over most of the surface. There is initially a significant discrepancy between the GASP and SRGULL values just downstream of the nozzle exit plane, but improves as the x-station moves downstream. This initial discrepancy is most likely due to the fact that SRGULL does not calculate the flow field below the external cowl, resulting in a different flow structure in the aftbody region when compared to the CFD predictions. Both codes predict that the effect of extending the cowl trailing edge is to cause the exhaust plume to expand less rapidly and increase the pressure over a large portion of the aftbody surface. The effect of cowl-trailing-edge deflections combined with a 0.508 -meter (20-inch) extension at Mach 6 is shown in figure 7. For each 5-degree deflection, a decrease in aftbody surface pressure results over some portion of the surface compared to the $0^{\circ}$ deflection case. This is due to the

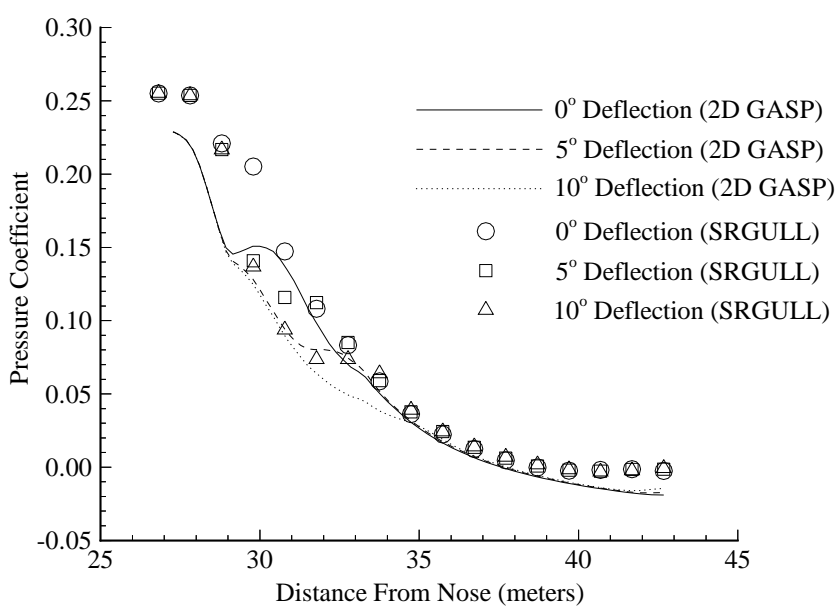

Figure 7. Effect of cowl-trailing-edge deflections for a 0.508 meter extension on aftbody surface pressures at Mach 6 .

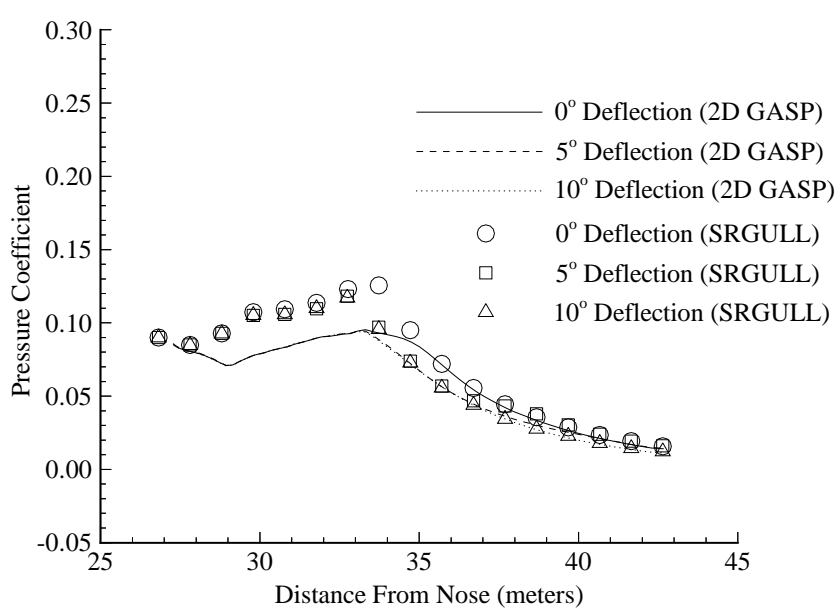

Figure 9. Effect of cowl-trailing-edge deflections for a 0.508meter extension on aftbody surface pressures at Mach 10.

additional expansion of the exhaust plume caused by the deflection. No change in the surface pressure values are observed downstream of the $\mathrm{x}=35$ meters location. Although not shown in the figure, a $5^{\circ}$ deflection produces a similar effect when combined with a 1.016-meter (40-inch) extension. Figures 8 and 9 show predictions for Mach 10 freestream conditions. The predictions show that there is no significant change in the comparative trends observed due to extensions and deflections between Mach 6 and 10, except that the surface pressure plateau effect, which begins at approximately the $\mathrm{x}=30$ meters location, is more pronounced at Mach 10.

A comparison of 2-D and 3-D center-line aftbody surface pressures from GASP at Mach 6 freestream conditions are shown in figures 10 and 11 . Figure 10 shows the baseline and 0.508 -meter (20-inch) extension cases while figure 11 shows the $0^{\circ}$ and $10^{\circ}$ deflection cases for the 0.508 -meter (20- 


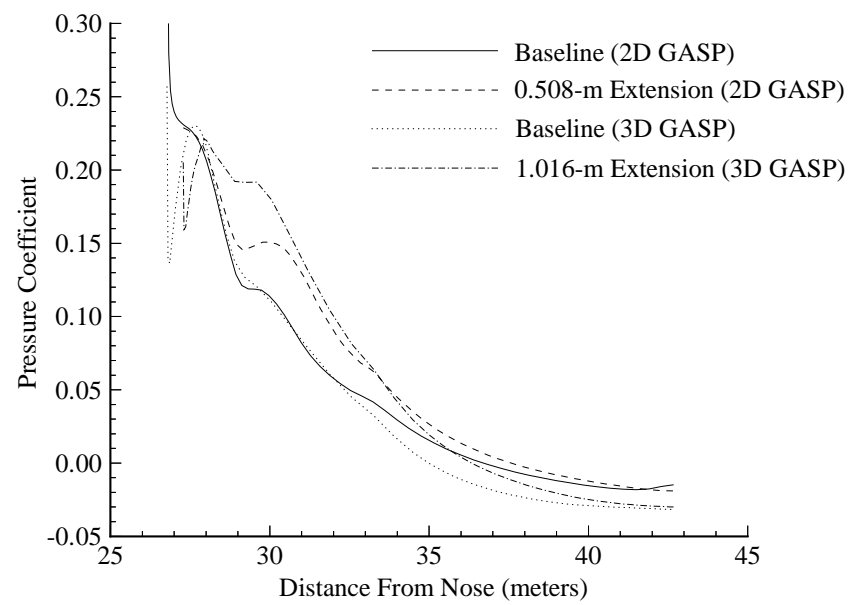

Figure 10. Comparison of center-line aftbody surface pressures for 2-D and 3-D GASP solutions of baseline and trailing-edge extension case at Mach 6 freestream conditions.

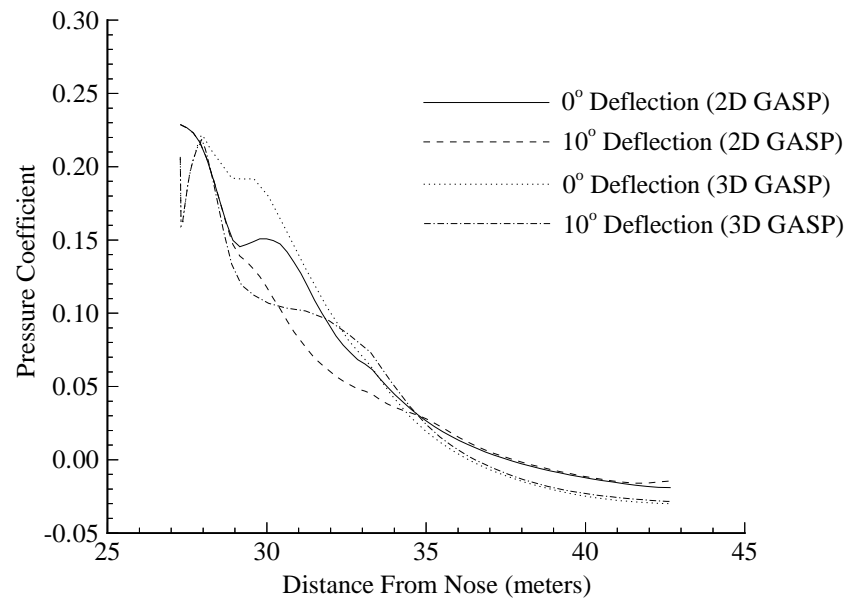

Figure 11. Comparison of center-line aftbody surface pressures for 2-D and 3-D GASP solutions of $0^{\circ}$ and $10^{\circ}$ trailing-edge deflection cases with $0.508-\mathrm{m}$ extension at Mach 6 freestream conditions.

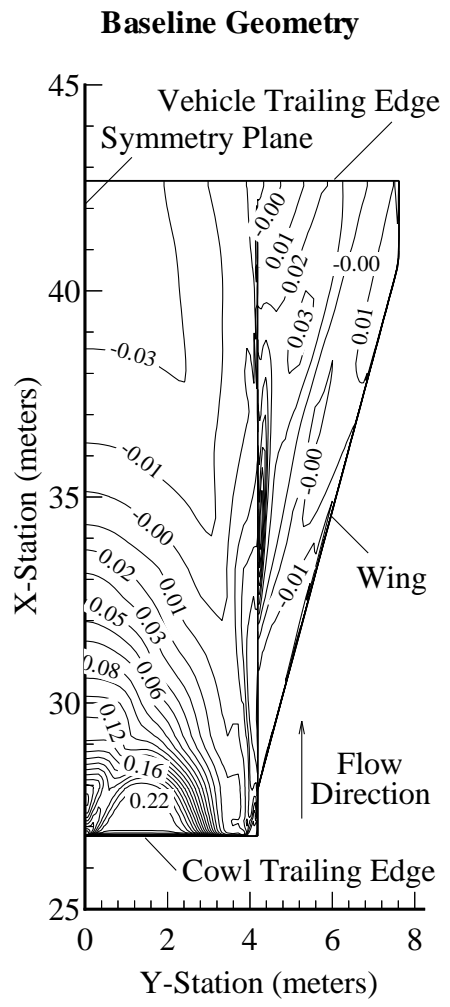

\subsection{8-meter (20") Extension $0^{\circ}$ Deflection}
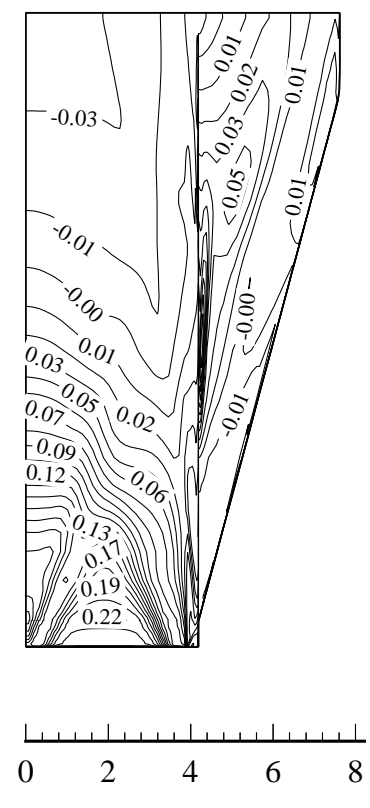

0.508-meter (20") Extension $10^{\circ}$ Deflection
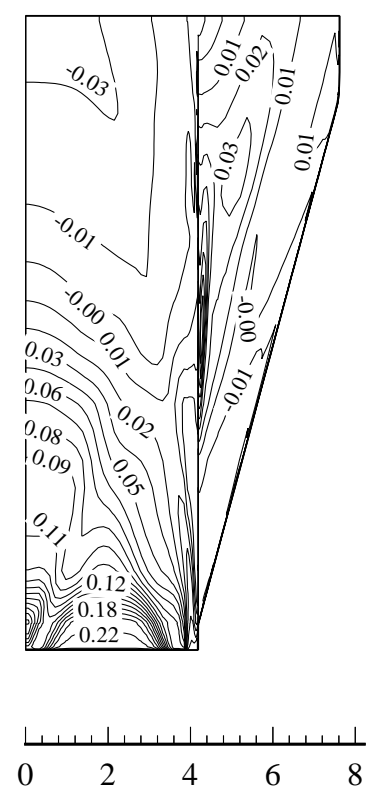

Figure 12. Comparison of aftbody surface pressure coefficient contours for 3-D GASP solutions at Mach 6 conditions.

inch) extension. The 3-D solutions all show a localized increase in pressure just downstream of the nozzle exit plane, caused by the 3D nature of the flow field exiting the nozzle. The 3-D solutions show higher surface pressures over the first part of the aftbody surface for similar geometries. However, at approximately the $\mathrm{x}=32$ to $\mathrm{x}=33$ meters location, the $3-\mathrm{D}$ solution begins to expand more rapidly than the 2-D case, resulting in lower surface pressures over the downstream portion of the aftbody surface. Aftbody surface pressures for 3-
D solutions with lines of constant pressure coefficient values labeled are shown in figure 12 for each of the 3-D solutions obtained. The lower surfaces of the aftbody (external nozzle) and wings are shown downstream of the nozzle exit plane. The internal nozzle geometry has a spanwise expansion on both sides of the nozzle, resulting in a spanwise variation in surface pressures at the cowl exit plane location. The surface pressure contours show that the same trends observed at the center-line exist off-center-line as well. The figure also indi- 
cates that modifying the cowl position also affects pressures on the lower surface of the wing. There is a localized region of higher pressure on the wing for the 0.508 -meter (20-inch) expansion case with $0^{\circ}$ deflection. This effect is diminished for the $10^{\circ}$ deflection case. Most areas of increased surface pressure over the baseline geometry exist on the external nozzle portion of the aftbody inboard of the wing, but the effect is not entirely confined to this surface.

Tables 5 and 6 show the integrated lift, thrust and pitching moment values for the SRGULL and 2-D GASP solutions at Mach 6 and Mach 10 conditions, respectively. The coefficients for the baseline geometry at each Mach number are presented with the percent changes produced by each geometry modification. Since the forebody and inlet representations are different, the predictions presented here represent integrated quantities over the internal nozzle (body-side and cowl-side) and aftbody surfaces. Since SRGULL does not compute the external cowl flow fields, the force and moment increments on the external side of the cowl were not computed. The changes are shown with respect to the baseline case to show the effects of cowl-trailing-edge extensions and with respect to the $0^{\circ}$ deflection case to show the effects of the trailing-edge deflections for a given extension length. In order to make comparisons between the two methods, the values shown are per-unit-width values. There is a considerable difference between the pitching moment coefficients predicted by GASP and SRGULL for the baseline geometry. This is due primarily to the differences in the trailing edge geometry, shown in figure 2 and discussed previously, and the discrepancies in aftbody surface pressures. Although the absolute values do not compare well, the trends in force and moment increments due to geometry changes can still be compared. At Mach 6, both SRGULL and the 2-D GASP solutions predict a decrease in lift and nose-up pitching moment and an increase in thrust from the cowl-trailing-edge extensions. The increases in thrust and pitching moment are due to the increased aftbody surface pressures, as previously noted. The decrease in lift is a result of the increased pressure and surface area on the cowl-side of the internal nozzle. Both codes predict a decrease in lift and thrust as well as an increase in nose-up pitching moment when the cowl-trailingedge is deflected from the $0^{\circ}$ case for a given extension length. The additional nose-up pitching moment is a result of the decreased aftbody surface pressures, despite the fact that a trailing edge deflection into the freestream flow tends to

\begin{tabular}{|c|c|c|c|}
\hline Mach 6 Conditions & $\mathrm{C}_{\mathrm{L}}$ & $\mathrm{C}_{\mathrm{T}}$ & $\mathrm{C}_{\mathrm{M}}$ \\
\hline Baseline SRGULL & 0.00355 & 0.00190 & -0.000526 \\
\hline Baseline GASP & 0.00279 & 0.00161 & -0.000257 \\
\hline \multicolumn{4}{|c|}{ \% Change From Baseline Case } \\
\hline 0.508-m ext. SRGULL & -9.01 & 11.6 & -15.8 \\
\hline 1.016-m ext. SRGULL & -19.7 & 21.6 & -38.2 \\
\hline 0.508-m ext. GASP & -13.6 & 13.7 & -49.4 \\
\hline 1.016-m ext. GASP & -24.4 & 25.5 & -102.7 \\
\hline \multicolumn{4}{|c|}{$\begin{array}{l}\% \text { Change From } 0^{\circ} \text { Deflection with } 0.508 \text {-meter } \\
\text { (20-inch) Extension }\end{array}$} \\
\hline $5^{\circ}$ defl. SRGULL & -0.93 & -1.42 & 5.91 \\
\hline $10^{\circ}$ defl. SRGULL & -1.86 & -2.83 & 11.3 \\
\hline $5^{\circ}$ defl. GASP & -0.42 & -1.09 & 8.33 \\
\hline $10^{\circ}$ defl. GASP & -0.83 & -1.64 & 18.2 \\
\hline \multicolumn{4}{|c|}{$\begin{array}{l}\text { \% Change From } 0^{\circ} \text { Deflection with 1.016-meter } \\
\text { (40-inch) Extension }\end{array}$} \\
\hline $5^{\circ}$ defl. SRGULL & -0.70 & -1.32 & 7.57 \\
\hline $5^{\circ}$ defl. GASP & -2.37 & -1.49 & 14.6 \\
\hline
\end{tabular}

\begin{tabular}{|l|l|l|l|}
\hline Mach 10 Conditions & $\mathrm{C}_{\mathrm{L}}$ & $\mathrm{C}_{\mathrm{T}}$ & $\mathrm{C}_{\mathrm{M}}$ \\
\hline Baseline SRGULL & 0.00339 & 0.00133 & -0.000986 \\
\hline Baseline GASP & 0.00307 & 0.00111 & -0.000857 \\
\hline \hline
\end{tabular}

\% Change From Baseline Case

\begin{tabular}{|l|l|l|l|}
\hline 0.508 -m ext. SRGULL & -6.78 & 5.26 & -10.5 \\
\hline $1.016-m$ ext. SRGULL & -15.9 & 9.77 & -19.0 \\
\hline 0.508 -m ext. GASP & -10.1 & 5.41 & -10.9 \\
\hline $1.016-m$ ext. GASP & -19.9 & 11.7 & -21.4 \\
\hline
\end{tabular}

$\%$ Change From $0^{\circ}$ Deflection with 0.508-meter (20-inch) Extension

\begin{tabular}{|c|c|c|c|}
\hline $5^{\circ}$ defl. SRGULL & -3.48 & -2.14 & 7.34 \\
\hline $10^{\circ}$ defl. SRGULL & -4.43 & -3.57 & 22.7 \\
\hline $5^{\circ}$ defl. GASP & -10.9 & -19.7 & 6.84 \\
\hline $10^{\circ}$ defl. GASP & 1.09 & 0.0 & 10.1 \\
\hline \multicolumn{4}{|c|}{$\begin{array}{l}\% \text { Change from } 0^{\circ} \text { Deflection with 1.016-meter } \\
\text { (40-inch) Extension }\end{array}$} \\
\hline $5^{\circ}$ defl. SRGULL & -3.86 & -2.05 & 12.0 \\
\hline $5^{\circ}$ defl. GASP & -2.03 & -0.81 & 13.9 \\
\hline
\end{tabular}

Table 6. Force and moment increments at Mach 10 from SRGULL and 2-D GASP predictions. 
produce a nose-down pitching moment. The significant difference in the percent increase between GASP and SRGULL is again due to the geometry modeling differences. Similar effects are also shown in table 6 for Mach 10 conditions, although the magnitude of the favorable pitching moment increments due to cowl extensions is less than at Mach 6. Another difference noted is that GASP predicts a small

\begin{tabular}{|l|l|l|l|}
\hline Mach 6 Conditions & $\mathrm{C}_{\mathrm{L}}$ & $\mathrm{C}_{\mathrm{T}}$ & $\mathrm{C}_{\mathrm{M}}$ \\
\hline Baseline & 0.04244 & 0.03455 & -0.00184 \\
\hline $\begin{array}{l}0.508-\mathrm{m} \text { ext. } \\
\text { (\% Change) }\end{array}$ & $\begin{array}{l}0.03674 \\
(-13.4)\end{array}$ & $\begin{array}{l}0.04690 \\
(+35.7)\end{array}$ & $\begin{array}{l}-0.00865 \\
(-370)\end{array}$ \\
\hline $\begin{array}{l}0.508-\mathrm{m} \text { ext./ } 10^{\circ} \text { defl. } \\
(\% \text { Change) }\end{array}$ & $\begin{array}{l}0.03663 \\
(-0.30)\end{array}$ & $\begin{array}{l}0.04706 \\
(+0.34)\end{array}$ & $\begin{array}{l}-0.00602 \\
(30.4)\end{array}$ \\
\hline
\end{tabular}

Table 7. Force and moment predictions from 3-D GASP solutions at Mach 6.

increase in lift for the $10^{\circ}$ deflection combined with a 0.508 meter extension case at Mach 10. It is noted that the trailingedge deflection would also produce an additional trim drag penalty when forces and moments on the external cowl surface are taken into account.

The integrated lift, thrust and pitching moment coefficient values are shown in table 7 for the 3-D GASP solutions. These values also represent quantities integrated over the internal nozzle and lower aftbody surfaces, including the wing lower surface. The absolute force and moment values cannot be compared directly since the 3D predictions represent integrated quantities over the full 3D surface as opposed to per-unit-width values. However, differences in trends will show the effect of modeling the full 3D geometry and flow field. The percent changes shown for the 0.508-meter extension are with respect to the baseline case, while the values shown for the $10^{\circ}$ deflection case are with respect to the $0^{\circ}$ deflection case. The same trends as observed in the 2-D predictions are apparent, but the magnitudes of the force and moment increments due to geometry modifications are greatly magnified. The trailing-edge extension provides a significant increase in thrust and nose-down pitching moment with a loss of lift. The cowl deflection is not as effective, producing a significant nose-up pitching moment with only slight changes in lift and thrust over the $0^{\circ}$ deflection case. The effect of more accurately modeling the state of the boundary layer (i.e., turbulent flow) would be primarily to decrease the thrust coefficient values, due to increased skin friction.

The results indicate that the cowl-trailing-edge extensions are more effective at providing additional trim moment capability than are cowl-trailing-edge deflections. In each case, the extensions produced a significant nose-down pitch- ing moment while actually providing an increase in thrust. The integrated values for the forebody and upper surfaces show that the vehicle has a substantial nose-up pitching moment at these conditions. Although the additional nosedown moment may not be enough to trim the vehicle, they reduce the required control surface deflection angle needed and the resulting trim drag penalty. In contrast, the trailing edge deflections resulted in additional nose-up pitching moment compared to a $0^{\circ}$ deflection for a given extension length. This modification still provides additional nose-down pitching moment when compared to the baseline case.

The final part of this analysis would be to make an assessment of how the magnitudes of the pitching moment increments produced by cowl-trailing-edge extensions and deflections compare with those produced by conventional control surfaces. This would give an indication of how much a conventional control surface deflection angle, and thereby the associated trim drag penalty, could be reduced. The most appropriate data available to make this comparison is that from the experimental study in reference 3. This report includes data for a two-percent scale model of the TTD configuration under powered exhaust simulation with various elevon deflection angles. An absolute comparison of force and moment increments cannot be made due to differences in Reynolds numbers and exhaust gas flow conditions. However, comparisons between the experimental data and the 3-D CFD predictions show that the magnitudes of the pitching moment increment produced by the 0.508 -meter cowl extension are comparable to that produced by a $10^{\circ}$ trailing-edgedown elevon deflection at the most closely matched conditions. ${ }^{3}$ Therefore, the pitching moment increments produced by cowl-trailing-edge extensions are significant and should result in a significant decrease in the control surface deflection angle required and the associated trim drag penalty.

\section{Concluding Remarks}

A study was conducted to examine the effects of using engine cowl-trailing-edge extensions and deflections to enhance the controllability of hypersonic airbreathing transatmospheric vehicles. A generic SSTO configuration known as the TTD was studied with 0.508-meter (20-inch) and 1.016-meter (40-inch) extensions of the cowl trailing edge as well as $5^{\circ}$ and $10^{\circ}$ deflections. Predictions were obtained at representative flight conditions at freestream Mach numbers of 6 and 10 using an engineering analysis code followed by 2 D and 3-D (at Mach 6 only) viscous computational solutions The CFD predictions showed the salient flow field features present and indicated that extensions and deflections of the cowl trailing edge do not significantly affect the macroscopic flow field characteristics. Differences in aftbody surface pressures between SRGULL and 2-D GASP solutions are due to geometry modeling differences and a more accurate computation of the external cowl and aftbody flow fields by GASP. However, the qualitative trends in the effects of geometry modifications on aftbody forces and moments compare 
well. The predictions show that cowl-trailing-edge extensions cause higher surface pressures over most of the aftbody surface when compared to the baseline geometry. A cowltrailing-edge deflection into the freestream (trailing edge down) causes lower aftbody surface pressures over some portion of the surface. The 3-D solutions confirm these observations and also show that the surface pressure increases are mostly confined to the portion of the aftbody surface inboard of the wings, except for the 0.508 -meter extension case with no deflection where a small localized increase in pressure is observed on the wing surface. Force and moment predictions show that the extensions are effective in providing additional nose-down pitching moment to trim the configuration as well as additional thrust. This pitching moment increment will decrease the deflection angle required from a conventional control surface and the associated trim drag, which can be significant at hypersonic speeds. Force and moment predictions also show that cowl-trailing-edge deflections contribute additional nose-up pitching moment as well as a loss in lift and thrust for most cases. Although not as effective as cowl extensions in providing additional force and moment increments, deflections may provide an additional capability for vehicle control.

\section{$\underline{\text { References }}$}

1. McIver, Duncan E. and Morrell, Frederick R.: National Aero-Space Plane: Flight Mechanics. 75th Symposium of the Flight Mechanics Panel on Space Vehicle Flight Mechanics, Paper No. 20, Luxembourg, France, November 13-16, 1989.

2. Shaugnessy, John D.; and Gregory, Irene M.: Trim Drag Reduction Concepts for Horizontal Takeoff Single-Stage-ToOrbit Vehicles. NASA Technical Memorandum No. 102687, December 1991.

3. Witte, David W.; Huebner; Lawrence D.; and Haynes, Davy A. Test Technique for Using Metric Model Parts to Obtain Powered Effects on Air-Breathing Configurations in Hypersonic Facilities. NASP Technical Paper No. 1008, October 1993.

4. Huebner, Lawrence D.; and Tatum, Kenneth E.: Computational Effects of Inlet Representation on Powered Hypersonic Airbreathing Models. Journal of Aircraft, volume 30, number 5, September-October 1993, pp. 571-577.

5. Tatum, Kenneth E.; Huebner, Lawrence D.; and Witte, David W.: Computational Study on the Use of Simulant Gas in Powered, Hypersonic Air-Breathing Models. NASP Technical Paper No. 1007, October 1992.

6. Witte, David W.; Huebner, Lawrence D.; and Monta, William J.: Hypersonic Powered Aftbody Testing with a Simulant Exhaust at Mach 6. 1992 NASP Mid-Term Technology
Review, Paper No. 286, NASP CP-11067, vol. IV, pp. 281314, April 1992.

7. Everhart, Joel L.; Ashby, George C.; and Monta, William J.: Experimental Surface Pressure and Flow Field Results on a Powered Simulation Model at Mach 6. 1993 NASP MidTerm Technology Review, Paper No. 37, April 1993.

8. Phillips, W.P.; and Cruz, C.I.: Hypersonic Aerodynamic Characteristics for Langley Test Technique Demonstrator. AIAA Paper 93-3443, August 1993.

9. Everhart, Joel L.; Dye, Thomas P.; Jones, Michael P.; and Daryabeigi, Kamran: Propulsion/Airframe Integration Testing in Langley 31-inch Mach 10 Tunnel. 10th NASP Technology Symposium, Paper No. 173, April 1991.

10. Dress, David A.; Boyden, Richmond P.; and Cruz, Christopher I.: Supersonic Dynamic Stability Characteristics of a Langley Test Technique Demonstrator NASP Configuration. NASP TP-1011, September 1993.

11. Boyden, Richmond P.; Dress, David A.; Fox, Charles H. Jr.; Huffman, Jarrett L.; and Cruz, Christopher I.: Subsonic Static and Dynamic Stability Characteristics of the Test Technique Demonstrator NASP Configuration. AIAA Paper 930519, 31st AIAA Aerospace Sciences Conference, January 1993.

12. Gatlin, Gregory M.; and Kjerstad, Kevin J.: Low-Speed Longitudinal Aerodynamic Characteristics of a Powered National Aero-Space Plane Test Technique Demonstrator Configuration In and Out of Ground Effect. NASP TP-1012, February 1994.

13. Huebner, Lawrence D.; and Haynes, Davy A.: Forebody Redesign and Flow Characterization of Test Technique Demonstrator at Mach 6. NASP Technical Paper 1013, April 1994.

14. Pinckney, S. Zane: SRGULL - An Advanced Engineering Model for the Prediction of Airframe Integrated Scramjet Cycle Performance. Available through COSMIC, University of Georgia, Athens, Georgia. Program No. LEW-15093.

15. McGrory, William D.; Slack, David C.; Applebaum, Mchael P.; and Walters, Robert W.: GASP Version 2.2 User's Manual. Aerosoft, Inc., Blacksburg, VA, 1993.

16. Richardson, Pamela F.; et. al. Hypersonic CFD Applications for the National Aero-Space Plane. Journal of Aircraft, volume 27, number 4, April 1990, pp. 300-305. 